\title{
How Knowledge Management helped Knowledge Intensive Business Services in Surviving COVID-19 and Creating Resiliency for New Normal: A Case Study of a GRC Training Firm in Indonesia
}

\author{
Ray Antonio ${ }^{1}$ \\ ${ }^{1}$ Enterprise Risk Management Academy, Indonesia
}

\begin{abstract}
Since early 2020, COVID-19 pandemic has attacked many business sectors in many countries. In Indonesia, the government reacts to this situation by issuing several regulations, one of which is the large-scale social restrictions (PSBB) regulation. This regulation affects many business sectors, including Knowledge Intensive Business Services (KIBS) sectors. KIBS sectors have been developing quickly, especially in developing countries like Indonesia. Knowledge plays a crucial part for KIBS firms as these firms depend heavily on their workers' knowledge. In this study, Lembaga Pelatihan Kerja Mitra Kalyana Sejahtera (LPK MKS) is being used as the research object for conducting the research. LPK MKS is a Governance, Risk, and Compliance (GRC) training firm, which included as one of KIBS business sectors. This study uses case study methodology by focusing on obtaining deep understandings about the knowledge management practices in KIBS training firm. The author obtains all the necessary data through in-depth qualitative interviews and secondary data. From the collected and analysed data, LPK MKS has implemented all of the success factors for managing knowledge. While the implementation of leadership and ICT are more notable, the implementation in organisational infrastructure is still not ideal. Nonetheless, the overall implementations of knowledge management help the firm in surviving the COVID-19 pandemic era and creating resiliency to face the new normal condition.
\end{abstract}

Keywords: Knowledge Management, KIBS

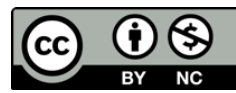

This is an open access article under the CC-BY-NC license.

\section{INTRODUCTION}

Starting from early 2020, COVID-19 pandemic has attacked many countries until now. Facing this pandemic, government from all across the world reacts differently. In Indonesia, the government reacts by issuing several regulations. While there are many regulations relating to the pandemic, one with the most impact to the business world is the large-scale social restrictions (PSBB) regulation. With this regulation, most non-essential business sectors could not open their offices, instead, they must work from home and adapt to the new normal situation. As one of the non-essential business sectors, knowledgebased firms are also impacted by the regulation.

Knowledge has progressively become more and more important in the business world. As stated by Giddens (1984), the knowledge economy gradually emerges to the business area. Hislop (2005) identifies that there are three reasons behind this phenomenon. First, knowledge has become central and valuable to the advanced economies. Second, knowledge is seen as the key to the organisational performance. Third, the nature of organisation has become more and more knowledge-intensify. Furthermore, several scholars agree that knowledge has become one of the many sources of organisations' competititve advantage (Mudambi, 2002; Bou-Llusar \& Segarra-Cipres, 2006).

Consistent with the developing realisation of the importance of knowledge, the business world has shifted from manufacturing into service industries. Since 1980, service business sector employment has been increasing, whereas manufacturing industries are decreasing (Sasaki, 2007). Whilst there are many varieties of service business types, one of the most developing types is the Knowledge Intesive Business Services (KIBS). KIBS encompass many sectors, such as computer services, research and development, economic services, technical services, and advertising (Simmie \& Strambach, 2006). Out of many economic service sectors in KIBS, training firm is included in this sector. Like other KIBS, training firms also rely heavily on professional knowledge (Miles, et al., 1995). Based on this situation, training firms 
RSF Conference Series: Business, Management and Social Sciences Vol. 1 (5), 47-54

How Knowledge Management helped Knowledge Intensive Business Services in Surviving COVID-19 and Creating Resiliency for New Normal: A Case Study of a GRC Training Firm in Indonesia

Ray Antonio

need to use knowledge effectively in delivering their services (Lahti \& Beyerlein, 2000). Consequently, knowledge management can be used as a way to make it effective.

While most KIBS development happened in developed countries, developing countries are also experiencing it. Likewise, Indonesia, as a developing country, encounters the same shift. KIBS sectors are arising, especially in training firms. One of the many training firms in Indonesia is Lembaga Pelatihan Kerja Mitra Kalyana Sejahtera (LPK MKS). As a Governance, Risk, and Compliance (GRC) training provider in the local area, LPK MKS is a growing firm with knowledge intensive activities.

Since LPK MKS is categorised as one of the non-essential business sectors in this pandemic era, the firm is heavily impacted by the government's regulation. However, this firm could still survive the pandemic situation and adapt to the volatile new normal condition until this paper is written. Therefore, using LPK MKS as the case study object, the main question is: "how does knowledge management enable KIBS training firm to survive the COVID-19 pandemic era and to be resilient in the new normal era?". Hopefully, this paper could be useful not only for the object firm, but also for other KIBS companies in the similar field.

\section{LITERATURE REVIEW}

\section{Knowledge Intensive Business Services (KIBS)}

KIBS is defined by (Miles, et al., 1995) as services in economic activities which are aimed to create, accumulate, or disseminate knowledge. Another definition is suggested by Toivonen (2006), who defined KIBS as adept companies who deliver services to other companies and organisations. Bettencourt, et al. (2002) described KIBS as companies who use accumulation, creation, or dissemination of knowledge as their primary value-added activities to satisfy the client's needs. From these definitions, Muller and Doloreux (2009) embrace them and come up with a definition of KIBS. They defined KIBS as service firms that have high knowledge intensify characteristically and give services to other companies.

KIBS have three principal characteristics; 1) they rely heavily upon professional knowledge, 2) either become the main sources of information and knowledge or become the intermediate inputs supplier for their clients' production processes, 3) become an important aspect for a business to keep on being competitive (Miles, et al., 1995). While there are many service business sectors under KIBS, Miles, et al. (1995) makes an overview of KIBS sectors which can be seen on Figure 1.

\begin{tabular}{|l|l|}
\hline \multicolumn{2}{|c|}{ Knowledge Intensive Business Services: an Overview } \\
\hline 1 & Accounting and bookkeeping \\
\hline 2 & Management consultancy (not only regarding new technologies) \\
\hline 3 & Specific building services (e.g. architecture, surveying, construction engineering, etc.) \\
\hline 4 & Facility management services \\
\hline 5 & Technical engineering services \\
\hline 6 & Research and development services (excluding university-based R\&D) \\
\hline 7 & R\&D consultancy \\
\hline 8 & Design (not only regarding new technologies) \\
\hline 9 & $\begin{array}{l}\text { Environmental services (e.g. environmental law, elementary waste disposal service, remediation, } \\
\text { environmental monitoring, scientific/laboratory service, etc.) }\end{array}$ \\
\hline 10 & Computer and information-technology-related services (including software services) \\
\hline 11 & Legal services (note that technology-related legal services form a growth area) \\
\hline 12 & Marketing and advertising \\
\hline 13 & Exploitation and trade in real estate \\
\hline 14 & Training (not only regarding new technologies) \\
\hline 15 & Specific financial services (e.g. securities and stock-market-related activities) \\
\hline 16 & Temporary labour recruitment services \\
\hline 17 & Press and news agencies \\
\hline
\end{tabular}

Figure 1 Knowledge-Intensive Business Services: an Overview (Source: Miles et al., 1995) 


\section{KNOWLEDGE MANAGEMENT}

Knowledge management is defined as the critical management process of knowledge to respond existing needs, identifying, and optimising knowledge assets to develop new opportunities (Kluge, et al., 2001). Wellman (2009) infers knowledge management as a separate discipline of lessons learned and techniques used for the management of existing knowledge. While there is a wide variety of knowledge management definitions, the most common definition used in many literatures is the one suggested by Davenport and Prusak (2000), which stated that "the knowledge management process consists of initiatives, practices, strategies, and systems, which sustain and enhance the storage, sharing, and creation of both tacit and explicit knowledge to enhance learning within firms and create value to increase firm performance". Furthermore, knowledge management objective is to maximise enterprise's knowledge-related effectiveness and returns from its knowledge assets and renew them constantly (Wiig, 1997). Additionally, according to Wong (2005), there are some factors which are critical for firms to become successful in managing their knowledge. These factors include strategy, processes, ICT, management leadership, organisation culture, measurement, organisational infrastructure, motivational aids, resources, training and education, and human resource management.

To exploit the knowledge resources and capabilities of an organisation, knowledge management strategy is an important matter (Hansen, et al., 1999; Zack, 1999; Beckman, 1999). There are two different strategies to manage knowledge, which can be categorised as codification and personalisation strategies (Hansen, et al., 1999). In the codification strategy, knowledge is codified and kept in databases, which later can be retrieved and used by everyone in the firm. In contrast, the personalisation strategy focuses on individual communication. In this strategy, knowledge is closely tied to the person who developed it and consequently the use of technology is not to store the knowledge, but to help the firm to facilitate communicating the knowledge. Furthermore, according to Zack (1999), there are three areas regarding knowledge management strategies. First, organisations must recognise the unique and valuable knowledge to their selves. Second, the knowledge resources and capabilities must be able to support the organisation's market position. Third, it is essential for the organisation to discover the link between the knowledge management strategies and processes. Hence, each of the knowledge management processes should be conducted by suitable strategies.

As one of the knowledge management's major components, knowledge management process is required to be done by the professional service firms (Alavi \& Leidner, 2001). Although there are many studies that have identified the processes of knowledge management (Radding, 1998; Heisig, 2001; BecerraFernandez, et al., 2004), most of the scholars believe that there are four core processes. These processes consist of (1) knowledge creation, (2) knowledge storage, (3) knowledge distribution, and (4) knowledge application. Knowledge creation refers to the ability of a firm to generate new content or modifies existing knowledge (Pentland, 1995; Alavi \& Leidner, 2001). Several instruments can be used to promote knowledge creation process. These instruments consist of the external knowledge acquisition, the setting up of interdisciplinary teams, and the enablers of various method to draw out tacit and explicit knowledge. External knowledge acquisition can be achieved through the training held by any third parties, while the interdisplinary teams can be created by involving the customers (Mertins, et al., 2001). To prevent firms from losing track to a large amount of obtained knowledge, knowledge storage process is taking a vital part. Knowledge storage enables firms to do a quick search for any needed information which lead to an effective knowledge sharing throughout the firm (Hislop, 2005). After stored, knowledge needs to be distributed throughout the organisations before it can be learned. The purpose of knowledge distribution is to deliver the right knowledge to the right person at the right time (Mertins, et al., 2001). Different distribution methods are determined by the interactions between the firm's technologies, techniques, and human resources. These differences will create a different impact on the distribution rate of the transferred knowledge. For example, knowledge distributed through a programmed channel will reduce the chance of questioning the validity of the transferred knowledge. Likewise, firms with traditional organisational structure and command will reduce the opportunities in knowledge distribution by minimising the interaction between technologies, techniques, and human resources. Alternatively, firms with horizontal organisational structure, encouragement, and open-door policy will accelerate the knowledge flow in the firm (Bhatt, 2001). After distributed, knowledge needs to be utilised into the products, processes, and services of a firm. To sustain its competitive advantage, firms need to locate the correct type and form of knowledge that is in line with the firm strategy. According to Bhatt (2001), knowledge application is being used to make a firm's knowledge more dynamic and significant in generating values. This application process can be seen through its contribution towards the firm's 
performance in decision-making process and performing tasks (Hislop, 2005). Since knowledge application is initiated by the entire knowledge management processes, it tends to be the most critical process in managing firms' knowledge (Alavi \& Leidner, 2001; Mertins, et al., 2001).

To achieve the desirable knowledge management process, there is an applicable system known as knowledge management systems (KMS). KMS are Information and Communication Technology (ICT)based systems created to support firms in managing their knowledge creation, storage, distribution, and application processes (Alavi \& Leidner, 2001). While not all knowledge management programs need help of the IT implementations, IT usage in it is not scarce. Some examples of KMS are electronic mail, document management, collaboration tools, Wiki, etc.

Referring to Horak (2001), management leadership performs as the key role in affecting the success of knowledge management. The person who is in charge of becoming a leader should perform as a role model in order to achieve the desired knowledge management. Another imperative factor for successful knowledge management is the organisational culture. A supportive culture will eventually lead to the encouragement of knowledge creation, sharing, and application. As stated by Goh (2002), a collaborative culture is vital to embolden the knowledge transfer between individuals and groups. Furthermore, it also inspires knowledge creation (Lee \& Choi, 2003). Next, measurement of knowledge management is necessary for tracking knowledge management progress within the organisation. Some available methods for organisations to do the measurement are balanced scorecard (Kaplan \& Norton, 1996) and intellectual capital metrics (Liebowitz \& Suen, 2000). However, there are still no complete method regarding the measurement for knowledge management in an organisation (Gupta, et al., 2000). Another critical success factor is organisational infrastructure. According to Davenport, et al. (1998), organisations need to set the roles and teams to execute knowledge-related activities. As suggested by Davenport and Volpel (2001), the role of Chief Knowledge Officer or equivalent is needed in order to coordinate, manage, and set the course for knowledge management. Without any motivation, individuals will be unenthusiastic to do knowledge management practice. Thus, motivational aids are needed for developing successful knowledge management within the organisation. While these aids can be done in many ways, the most common motivational aids are taken in the form of incentives and rewards (Hauschild, et al., 2001). Next, financial support and human resources, which can be categorised as organisation resources, are important in implementing knowledge management. Financial support is required to make the knowledge management system happen, whilst human resources are compulsory to manage and coordinate the implementation process as well as to take up the knowledge-related roles. Human resources need a proper training and education to understand the knowledge management concept. According to Yahya and Goh (2002), training and education related to team building, creativity, problem solving, and documentation skills are showing positive impacts to the overall knowledge management process. Lastly, human resource management (HRM) is another factor that influence the success rate of knowledge management implementation. As discussed by many authors (Harman \& Brelade, 2000; Garavan, et al., 2000; Soliman \& Spooner, 2000), the main issues in HRM are the employee recruitment, development, and retention. Effective recruitment is a vital process as it determines the incoming knowledge and competences into the organisation; therefore, employees with the desired knowledge and skill should be recruited. Furthermore, according to Wong (2005), employees' competences and skills need to be continuously developed to produce more valuable contributions to the organisation. When the knowledge workers do not get the correct development, their value will be depreciating; thus, appropriate professional development activities are encouraged to be developed within the organisation. Finally, due to the nature of knowledge-based organisation, organisations need to retain their employees from leaving the job. To minimise this issue, organisations can provide opportunities for the employees to grow and to advance their career. Another way to do it is by giving the employees a conducive working environment to make them satisfied with their job (Harman \& Brelade, 2000).

\section{RESEARCH METHODOLOGY}

Case study methodology is being used for this research. By choosing this methodology, this research could 'tell-it-like-it-is' from the respondent's point of view (Stark \& Torrance, 2005). Moreover, this research is mainly conducted using qualitative research method. According to Cresswell (2003), qualitative research is exploratory in nature where the researcher seeks to listen to the respondents and build interpretation based on their ideas. Therefore, in this research, the researcher/author "interact closely with those they study and minimise the distance between themselves in order to gather detailed and subjective 
information" (Cresswell, 1994). The analysis is then realised by linking the concept found during literature review with the empirical data (Coffey \& Atkinson, 1996).

This research uses two instruments to collect empirical evidence: semi-structured individual depth (indepth) interviews and secondary data. For the first instrument, in selecting the interviewees for this research, two selection criterias are being used: (1) interviewee must be an official LPK MKS employee for at least 3 years and (2) interviewee must be at least on the middle management level within the firm. From the selection criteria, five employees are selected to be interviewees for this research, which consists of two middle management level employees, two senior management level employees, and one director. Interviews are carried out via electronic mail (e-mail) and video conference platform (Zoom and Google Meet) for about 30-45 minutes per interviewee. Also, these interviews are conducted in Bahasa Indonesia to help the interviewees provide as many detailed information as possible for this research. For the second instrument, secondary data, are collected mostly from the firm's website which contain the firm's profile, vision, mission, programs, etc.

\section{FINDING AND DISCUSSION}

LPK MKS has around 50 employees consisting of back-office employees and external experts. With this number of people, LPK MKS believes that the most suitable knowledge management strategy for the firm is codification strategy by using integrated database system. Furthermore, since most of LPK MKS' employees are not coming from the same city, high technology usage in distributing knowledge is needed to help them in getting fast access to new knowledge.

As for knowledge management process, LPK MKS starts from knowledge creation process. There are two regular activities alongside with two irregular activities that can be seen as the way of obtaining knowledge. The regular activities consist of strategic progress update meeting and feedback form distribution, whereas the irregular activities composed of research team support and external information or input collection. In the monthly strategic progress update meeting, knowledge is created when internal employees exchange their ideas. In contrast, after-event feedback form distribution captures information and knowledge from the customers. For the irregular activities, depends on the leader's request, research team is usually searching and understanding the concept behind new knowledge. Afterwards, the team will write down the summary of the findings or create a new training material from the new knowledge. The other irregular activity, external information or input collection is usually done by the program and marketing officer. Usually, they collect information and input obtained from the external experts or/and customer on the training spot. The second process, knowledge storage, is being done by updating or inputting knowledge into the database. For safety reason, not every employee could input or update into the database, for example, regular admin could only input or update internal employee and customer details, while research team could only input or update training materials. The third process, knowledge distribution, is being done through various ways, such as meetings, e-mailing systems, and database usage. Even though there are many ways, the most common distribution is done via database usage. After getting the knowledge, the fourth process, knowledge application, begins. From the obtained knowledge, employees could create a better decision-making regarding things that are already available on the database. For the external experts, new knowledge such as training materials could enrich their training delivery. Furthermore, the knowledge application process helps the employees in increasing the firm's overall performance.

To ensure a smooth knowledge management process, LPK MKS invests heavily on the ICT system. This investment is done a year prior to the pandemic. Therefore, this investment is a proactive move from the firm in managing its knowledge in general, and not a reactive move due to the COVID-19 pandemic. While the system cannot be said to be dedicated only for knowledge management system, it really helps LPK MKS to accelerate the knowledge distribution rate especially in the pandemic and new normal situation where Indonesia government are implementing unpredictable large-scale social restrictions (PSBB) regulation from time to time. Regarding the ICT system itself, in line with the codification strategy, LPK MKS is using a dedicated private server to create a private integrated database that could only be accessed by its employees. Internal employees could access most of the data from the database, while external experts could only access data related to their jobs. For example, administration officer could access data about training materials, internal employee details, customer details, external expert details, and 
assignment details; whilst external experts could only access their own details, assigned training materials, assigned customer details, and assignment details.

Next, all the interviewees agree that the director's leadership is seen to be the most critical success factor in managing LPK MKS' knowledge. LPK MKS' director started a business system transformation within the firm from traditional into ICT system before COVID-19 pandemic even began. At the beginning of this transformation, the director had to force the employees to become familiar with the ICT system usage. Most employees were demotivated when they know that they should study and implement new system. Knowing this, as there is no Chief Knowledge Officer (CKO) in the firm, the director played the organisational infrastructure role equivalent to a CKO by making himself getting used to the ICT system before forcing it to his employees. When the employees knew that their director makes a great effort for this, they began to follow his steps. From this event, the firm's culture is beginning to change step by step into the one targeted by the director where everybody uses ICT system. This culture change process is also supported by the firm's incentive regulation as its motivational aid for the employees. The incentive calculation itself is based on employees' performance which are measured by doing monthly meeting and using key performance indicator (KPI). Monthly meeting is being used to measure and ensure that all employees have the same understanding regarding an issue, situation, or new knowledge, while KPI is being used to measure the knowledge implementation for each employee individually.

Regarding resources, LPK MKS supports knowledge management implementation through financial and human aspect. Financial aspect can be seen from the heavy investment made for the ICT system, while human aspect can be seen from the human resource management, especially on the recruitment process. LPK MKS only hires people that have suitable knowledge for the position and are suitable to the firm's culture. After hired, these people will have to undertake probation period for a certain amount of time before they could become an official LPK MKS employee. Knowing that employees are important asset for the firm, LPK MKS always give tailored training and education for the employees. For example, all employees get training and education regarding how to use LPK MKS database during the probation period, however, after finishing that period, the employees will get a more focused training and education, e.g., finance officer gets financial database training and education, while administration officer gets customer database training and education.

Since most of these factors are already implemented before COVID-19 pandemic began, LPK MKS has already become used to managing knowledge through ICT system. Therefore, when the pandemic began to spread, LPK MKS only needs to do what it always used to do regarding knowledge management. Furthermore, since LPK MKS has gotten used to this knowledge management practice, it became more resilient in facing the new normal volatility where government's regulations are keep changing.

\section{CONCLUSION AND FURTHER RESEARCH}

LPK MKS has proactively implemented most of the knowledge management success factors even before COVID-19 pandemic began, except for organisational infrastructure where the implementation is not ideal as the firm still uses its director in doing the CKO role. While everything is helpful for LPK MKS' success in managing knowledge, there are two notable success factors in surviving the pandemic and adapting to the new normal condition, which are the great leadership from the director in handling knowledge management and the application of knowledge management system using ICT system. MKS director's leadership enable the firm to survive by forcing the employees to adapt to the new business model even before the pandemic began. This adaptation is successful because the director did it first before forcing it to the employees. ICT system, as the other notable success factor, enables MKS employees to easily transfer knowledge from one to another even without meeting with each other. Since Indonesia government's regulation regarding the large-scale social restrictions (PSBB) in the pandemic and new normal era is unpredictable, ICT system usage is crucial in assuring that the firm could still transfer knowledge and do its business. Additionally, due to its number of study object limitation, further research is required to explore broader samples regarding knowledge management success factors in KIBS. Although this paper has its limitation, hopefully it could be useful for similar KIBS sectors to survive the COVID-19 pandemic and obtain resiliency in the volatile new normal condition through knowledge management. 


\section{REFERENCES}

Alavi, M. \& Leidner, D., 2001. Review: knowledge management and knowledge management systems: conceptual foundations and research issues. MIS Quarterly, 25(1), pp. 107-136.

Becerra-Fernandez, I., Gonzalez, A. \& Sabherwal, R., 2004. Knowledge Management: Challenges, Solutions, and Technologies. New Jersey: Pearson Education Inc..

Beckman, T., 1999. The Current State of Knowledge Management. Knowledge Management Handbook, pp. $1-22$.

Bettencourt, L. A., Ostrom, A. L., Brown, S. W. \& Roundtree, R. I., 2002. Client Co-Production in KnowledgeIntensive Business Services. California Management Review, Volume 44, pp. 100-128.

Bhatt, G. D., 2001. Knowledge management in organizations: examining the interaction between technologies, techniques, and people. Journal of Knowledge Management, 5(1), pp. 68-75.

Bou-Llusar, J. C. \& Segarra-Cipres, M., 2006. Strategic Knowledge Transfer and Its Implications for Competitive Advantage: An Integrative Conceptual Framework. Journal of Knowledge Management, 10(4), pp. 100-112.

Coffey, A. \& Atkinson, P., 1996. Making Sense of Qualitative Data. London: Sage Publication.

Cresswell, J. W., 1994. Research Design: Qualitative and Quantitative Approaches. London: Sage Publication.

Cresswell, J. W., 2003. Research Design: Qualitative, Quantitative and Mixed Methods Approaches 2nd Edition. Sage, Thousand Oaks, CA.

Davenport, T. H., De Long, D. W. \& Beers, M. C., 1998. Successful knowledge management projects. Sloan Management Review, 39(2), pp. 43-57.

Davenport, T. H. \& Prusak, L., 2000. Working knowledge: How organizations manage what they know. Harvard Business School Press, pp. 1-7.

Davenport, T. H. \& Volpel, S. C., 2001. The rise of knowledge towards attention management. Journal of Knowledge Management, 5(3), pp. 212-221.

Garavan, T. N., Gunnigle, P. \& Morley, M., 2000. "Contemporary HRD research: a triarchy of theoretical perspectives and their prescriptions for HRD. Journal of European Industrial Training, Volume 24, pp. 65-93.

Giddens, A., 1984. The Constitution of Society: Outline of the Theory of Structuration.

Goh, S. C., 2002. Managing effective knowledge transfer: an integrative framework and some practice implications. Journal of Knowledge Management, 6(1), pp. 23-30.

Gupta, B., Lakshmi, S. I. \& Aronson, J. E., 2000. Knowledge management: practices and challenges. Industrial Management \& Data Systems, 100(1), pp. 17-21.

Hansen, M. T., Nohria, N. \& Tierney, T., 1999. What's Your Strategy for Managing Knowledge?. Harvard Business Review, 77(2), pp. 106-116.

Harman, C. \& Brelade, S., 2000. Knowledge management and the role of HR. London: Prentice Hall.

Hauschild, S., Licht, T. \& Stein, W., 2001. Creating a knowledge culture. The McKinsey Quarterly, Issue 1, pp. 74-81.

Heisig, P., 2001. Business Process Oriented Knowledge Management. Knowledge Management: Best Practices in Europe, pp. 13-36.

Hislop, D., 2005. Knowledge Management in Organizations: A Critical Introduction. Oxford: Oxford University Press.

Horak, B. J., 2001. Dealing with human factors and managing change in knowledge management: a phased approach. Topics in Health Information Management, 21(3), pp. 8-17.

Kaplan, R. S. \& Norton, D. P., 1996. Using the Balanced Scorecard as a Strategic Management System. Harvard Business Review, 74(1), pp. 75-85.

Kluge, J., Stein, W. \& Licht, T., 2001. The McKinsey Global Survey of Knowledge Management: Knowledge Unplugged. s.l.:Palgrave Macmillan UK.

Lahti, R. K. \& Beyerlein, M. M., 2000. Knowledge Transfer and Management Consulting: A Look at "The Firm". Business Horizons, Issue 43 (1), pp. 65-74.

Lee, H. \& Choi, B., 2003. Knowledge management enablers, processes, and organizational performance: an integrative view and empirical examination. Journal of Management Information Systems, 20(1), pp. 179-228.

Liebowitz, J. \& Suen, C. Y., 2000. Developing knowledge management metrics for measuring intellectual capital. Journal of Intellectual Capital, 1(1), pp. 54-67.

Mertins, K., Heisig, P. \& Vorbeck, J., 2001. "Introduction", in Knowledge Management: Best Practices in Europe. pp. 1-10. 
Miles, I. et al., 1995. Knowledge-intensive business services: users, carriers and sources of innovation, Brussels: European Commission.

Mudambi, R., 2002. Knowledge Management in Multinational Firms. Journal of International Management, Volume 8, pp. 1-9.

Muller, E. \& Doloreux, D., 2009. What we should know about knowledge-intensive business services. Technology in Society, Volume 31, pp. 64-72.

Pentland, B. T., 1995. Information Systems and Organizational Learning: The Social Epistemology of Organizational Knowledge Systems. Accounting, Management and Information Technologies, 5(1), pp. 1-22.

Radding, A., 1998. Knowledge Management: Succeeding in the information-based Global Economy. Charleston: Computer Technology Research Corp..

Sasaki, H., 2007. The rise of service employment and its impact on aggregate productivity growth. Structural Change and Economic Dynamics, Volume 18, pp. 438-459.

Simmie, J. \& Strambach, S., 2006. The contribution of KIBS to innovation in cities: an evolutionary and institutional perspective. Journal of Knowledge Management, Issue 10 (5), pp. 26-40.

Soliman, F. \& Spooner, K., 2000. Strategies for implementing knowledge management: role of human resources management. Journal of Knowledge Management, 4(4), pp. 337-345.

Stark, S. \& Torrance, H., 2005. 'Case Study', in Research Methods in the Social Sciences, B. Somekh \& C. Lewin (eds.). Sage Publication, London, pp. 33-40.

Toivonen, M., 2006. Future prospects of knowledge-intensive business services (KIBS) and implications to regional economies. ICFAI Journal of Knowledge Management, 4(3), pp. 18-39.

Wellman, J., 2009. Organizational learning: How companies and institutions manage and apply knowledge. New York: Palgrave Macmillan.

Wiig, K. M., 1997. Knowledge Management: An Introduction and Perspective. The Journal of Knowledge Management, 1(1), pp. 6-14.

Wong, K. Y., 2005. Critical success factors for implementing knowledge management in small and medium enterprises. Industrial Management \& Data Systems, 106(3), pp. 261-279.

Yahya, S. \& Goh, W. K., 2002. Managing human resources toward achieving knowledge management. Journal of Knowledge Management, 6(5), pp. 457-468.

Zack, M. H., 1999. Developing a knowledge strategy. California Management Review, 41(2), pp. 125-145. 